\title{
Chitooligosaccharides and N-acetyl-D-glucosamine stimulate peripheral blood mononuclear cell-mediated antitumor immune responses
}

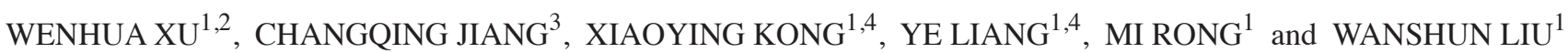 \\ ${ }^{1}$ College of Marine Life Sciences, Ocean University of China; ${ }^{2}$ Medical College, Qingdao University; \\ ${ }^{3}$ Department of Pathology, Municipal Hospital of Qingdao; ${ }^{4}$ Central Laboratory, \\ Affiliated Hospital of Qingdao University, Qingdao, Shandong, P.R. China
}

Received March 12, 2012; Accepted May 8, 2012

DOI: $10.3892 / \mathrm{mmr} .2012 .918$

\begin{abstract}
The aim of the present study was to evaluate the anticancer effects of chitooligosaccharides (COS) and N-acetylD-glucosamine (NAG), as well as to investigate the possible mechanisms involved. MTT assay and flow cytometry were used to evaluate the effect of various concentrations of COS and NAG on the proliferation and differentiation of peripheral blood mononuclear cells (PBMCs). In addition, sarcoma 180 cells were transplanted into mice to establish a tumor model. COS and NAG were administered by gavage of various doses. The tumor inhibition rate, thymus and spleen indexes, natural killer (NK) cell activity, and interleukin-2 (IL-2) and interferon- $\gamma$ $(\mathrm{IFN}-\gamma)$ serum levels were detected. Vascular endothelial growth factor (VEGF) expression levels, an important marker of angiogenesis, were also detected. As shown by immunohistochemistry, VEGF mRNA expression was decreased following treatment with COS and NAG, indicating that COS and NAG have an inhibitory effect on the expression of VEGF. The results from this study indicate that COS administered at a dose of $100 \mathrm{mg} / \mathrm{kg}$ and NAG at a dose of $300 \mathrm{mg} / \mathrm{kg}$ or $500 \mathrm{mg} / \mathrm{kg}$ can not only promote the differentiation of PBMCs and the secretion of IL-2 and IFN- $\gamma$, but can also inhibit the expression of VEGF mRNA in sarcoma 180 tumors. Our results show that the antitumor and immunoregulatory effects of COS and NAG are dose-dependent. Furthermore, the antitumor effect is achieved by the improvement of immunoregulation indirectly.
\end{abstract}

\section{Introduction}

The serious side-effects of chemotherapeutic agents have greatly limited their applications in the treatment of tumors (1).

Correspondence to: Professor Wanshun Liu, College of Marine Life Sciences, Ocean University of China, 5 YuShan Street, Qingdao, Shandong 266003, P.R. China

E-mail: wanshunliu@yahoo.cn

Key words: chitooligosaccharides, N-acetyl-D-glucosamine, antitumor, immunoregulation
For instance, cyclophosphamide is one of the most frequently used chemotherapeutics with serious side-effects, such as immunodepression and water intoxication, which can result in infections and hyponatremia, respectively. However, organic water-soluble antitumor agents, which have minor toxicity and fewer side-effects, are entering the spotlight of tumor therapy research, and are currently under investigation.

Chitooligosaccharides (COS) and N-acetyl-D-glucosamine (NAG) are two favorable organic agents, which have potential antitumor effects, with the advantages of being abundant in nature, having good biological properties and particular physiochemical characteristics. COS, composed of 3-10 $\mathrm{N}$-acetyl-D-glucosamine molecules or glucosamine molecules, is the enzymolysis lytic or chemical hydrolytic product of chitosan (2). NAG, a type of special monosaccharide, is also degraded from chitosan. COS and NAG have much better solubility compared with chitosan or chitin, and can be absorbed easily. They also have various beneficial biological functions, such as the enhancement of immune responses, anti-bacterial functions and the promotion of wound healing (2).

It has previously been demonstrated that COS and NAG have significant antitumor functions, through various mechanisms, such as inhibiting the proliferation of tumor cells, inducing necrosis and apoptosis, influencing angiogenesis and enhancing host immunity. It has been suggested that the bio-activity of COS and NAG is mainly due to their cationic properties which are attributed to the amino groups. The immunostimulatory property of COS is attributed to its $\mathrm{N}$-acetyl-chitohexaose group, though it has no cationic property (3). In addition, the molecular weight and deacylation degree also play an important role in the antitumor activities of COS $(4,5)$.

It has been reported that the growth and transformation of tumor cells is closely related to the angiogenesis of tumors (6). The vascular endothelial growth factor (VEGF) is one of the most important cytokines that have effects on angiogenesis. The VEGF-VEGF receptor (VEGFR), angiopoietin (Ang)-Tie2 and delta-like ligand4 (Dll4)-Notch have been found to be significant signaling pathways of angiogenesis. VEGFR2 is one of the most important molecules. Therefore, the inhibition of the VEGF signaling pathway may be a good strategy for treating malignancies. 
It has been well documented that COS, especially hexaacetyl-chitohexaose, has good antitumor activity. However, the antitumor effect of NAG has not been extensively studied. In the current study, the inhibitory effect of COS and NAG on cell proliferation in sarcoma 180 tumor cells was investigated in vitro and in vivo. Moreover, the natural killer (NK) cell activity, as well as serum interleukin-2 (IL-2) and interferon- $\gamma$ (IFN- $\gamma$ ) levels were measured, in order to elucidate the mechanisms involved in the tumor inhibitory effect of NAG.

\section{Materials and methods}

Reagents. COS and NAG were supplied by Qingdao Biotemed Biomaterial Co., Ltd. (Qingdao, China). Polyclonal anti-mouse VEGF primary antibody and polyclonal anti-mouse fibroblast growth factor-2 (FGF-2) primary antibody were purchased from Wuhan Boshide Experimental Equipment Co., Ltd. (Wuhan, China). The mouse IL-2 ELISA kit and mouse IFN- $\gamma$ ELISA kit were purchased from the R\&D Systems (Minneapolis, MN, USA). The sarcoma 180-bearing mice were obtained from Jinan DingGuo Biotech. Co. Ltd. (Jinan, China). All animal experiments were performed according to the rules approved by the Animal Protection Committee of Qingdao University, Qingdao, China.

Peripheral blood mononuclear cell (PBMC) preparation. Human venous blood $(50 \mathrm{ml})$ was obtained and then anticoagulated with sodium citrate. PBMCs were collected by density gradient centrifugation. Cells were cultured with GT-T551 medium containing autologous serum at $37^{\circ} \mathrm{C}(5 \%$ $\left.\mathrm{CO}_{2}\right)$ as described previously $(7,8)$.

Cell treatments with COS or NAG. The PBMCs were placed in 96-well plates at a concentration of $10^{6}$ cells $/ \mathrm{ml}(100 \mu 1$ per well). COS or NAG were added to the medium to obtain concentrations of $500,300,100$ or $50 \mu \mathrm{g} / \mathrm{ml}$. The PBMCs cultured with normal medium were the positive controls. The cells were observed under a microscope and imaged. To assess the effect of various concentrations of COS and NAG on the proliferation and viability of the PBMCs, the samples were analyzed with the MTT method on the 2nd and the 4th day from the beginning of the treatments.

Apoptosis detection. The PBMCs were treated with COS or NAG in 96-well plates as described above. On the 8th day after cell seeding, $8 \mu \mathrm{l}$ of acridine orange (AO)/ethidium bromide (EB) dyes were added into $200 \mu 1$ of cell suspensions. Fluorescence microscopy was performed and apoptotic rates were calculated.

Flow cytometry. PBMCs $\left(10^{6}\right.$ cells) treated with $500,100,50$, or 10 COS or NAG were collected. Cells were washed with PBS buffer, and subsequently incubated with anti-human-CD3FITC and CD4-PI, CD8-PI or CD56-PI monoclonal antibody. The cells were analyzed using a flow cytometer to detect the subgroups of $\mathrm{CD}^{+}{ }^{+} \mathrm{CD} 4^{+}$lymphocytes, $\mathrm{CD}^{+}{ }^{+} \mathrm{CD} 8^{+}$lymphocytes and $\mathrm{CD} 3{ }^{-} \mathrm{CD} 56^{+} \mathrm{NK}$ cells as described previously (9).

Animal experiments. Sarcoma 180 cells were injected into the peritoneal cavity of the sarcoma 180 -bearing mice. They were harvested from the peritoneal cavity of the tumor-bearing mice 7-9 days after inoculation, and suspended in an air-saturated phosphate buffer solution (10). The cells were then collected by centrifugation and resuspended in PBS at a concentration of $10^{7}$ cells $/ \mathrm{ml}$ and were subcutaneously transplanted into the right oxter region of the mice to obtain solid tumors. At day 1 post-inoculation, 80 mice were randomly divided into 8 groups. COS and NAG solutions at the doses of 100,300 and $500 \mathrm{mg} / \mathrm{kg}$, were administered by gavage every 2 days over a period of 15 days. The negative control group received $0.9 \%$ normal saline. The positive control group received cyclophosphamide $(300 \mathrm{mg} / \mathrm{kg})$.

At day 16 after subcutaneous transplantation, the mice were weighed and sacrificed. The solid tumor, thymus and spleen were weighed. The rate of inhibition of the growth of tumors was calculated as follows: inhibitory rate $(\%)=$ [(A-B)/A] $\times 100 \%$, where $\mathrm{A}$ is the mean tumor weight of the negative control group and $\mathrm{B}$ is the mean tumor weight of the COS-, NAG-treated or positive control group. The thymus and spleen indexes were expressed as the thymus or spleen weight relative to the body weight as described previously $(11,12)$.

The spleens were aseptically collected from each mouse and placed onto a 200-micron steel mesh immersed in chilled Iscove's modified Dulbecco's medium (IMDM). The spleen was passed through the steel sieve and collected in IMDM. Splenic lymphocytes $(100 \mu \mathrm{l})$ from each group were cultured in 96-well plates at $1 \times 10^{7}$ cells $/ \mathrm{ml}$ in IMDM as effector cells. YAC-1 cells $(100 \mu \mathrm{l})$ were used as the target cells, and added at $2 \times 10^{5}$ cells $/ \mathrm{ml}$ to obtain an effector/target $(\mathrm{E} / \mathrm{T})$ ratio of $0: 1$. The plates were then incubated for $12 \mathrm{~h}$ at $37^{\circ} \mathrm{C}$ in a $5 \% \mathrm{CO}_{2}$ atmosphere. NK cell activity was analyzed by measuring mitochondrial activity using the MTT assay and the absorbance was measured at $490 \mathrm{~nm}$ on an automated plate reader. Three types of control measurements were performed: target cell control, effector cell control and blank control. NK cell activity was calculated as follows: NK activity $(\%)=\left[1-\left(\mathrm{OD}_{\mathrm{E}+\mathrm{T}^{-}} \mathrm{OD}_{\mathrm{E}}\right) / \mathrm{OD}_{\mathrm{T}}\right]$ $\mathrm{x} 100 \%$, where ODT is the optical density value of the target cell control, $\mathrm{OD}_{\mathrm{E}+\mathrm{T}}$ is the optical density value of the test samples and $\mathrm{OD}_{\mathrm{E}}$ is the optical density value of effector cell control.

Blood was collected on day 16 after the administration of COS and NAG by gavage and maintained at room temperature for $4 \mathrm{~h}$ with natural coagulation, followed by centrifugation at $1,500 \mathrm{rpm}$, and the supernatants were used for the ELISA determination of IL- 2 and IFN- $\gamma$ levels.

Immunohistochemistry. Slides from the paraffin blocks of mice were deparaffinized and treated in Tris-EDTA solution. After peroxidase blocking reagent treatment, the anti-VEGF (1:100) primary antibodies were applied to the slides. Secondary goat anti-mouse antibody was used in this experiment. Samples were viewed under a microscope and imaged.

ELISA. The microtiter plates were pre-coated with an antibody specific to IL-2 or IFN- $\gamma$. Standards or samples were then added to the appropriate microtiter plate wells with a biotin-conjugated polyclonal antibody preparation specific for IL-2 or IFN- $\gamma$. Subsequenlty, avidin conjugated to horseradish peroxidase (HRP) was added to each microplate well and incubated. A TMB substrate solution was then added to each well. The color change was measured at a wavelength of $450 \mathrm{~nm}$. 

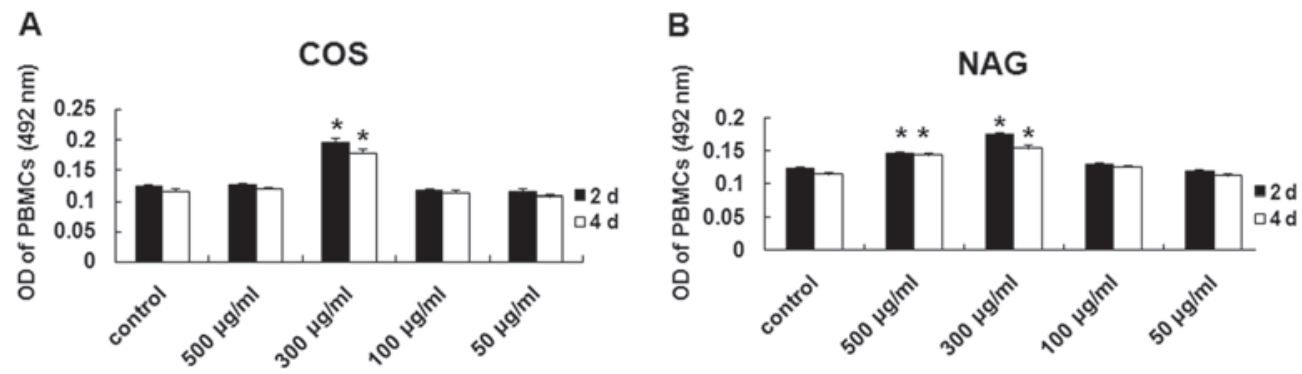

Figure 1. (A) Proliferation of leukomonocytes examined by MTT assay after culturing for 2 and 4 days (control and COS groups). (B) Proliferation of leukomonocytes examined by MTT assay after culturing for 2 and 4 days (control and NAG groups). COS, chitooligosaccharides; NAG, N-acetyl-D-glucosamine.

A

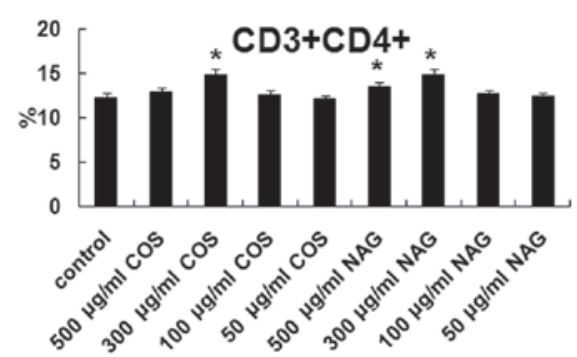

B

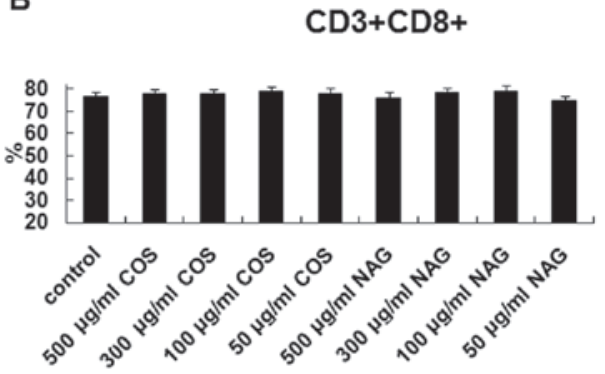

C

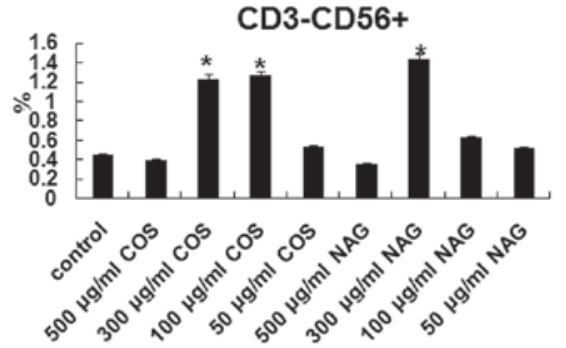

Figure 2. (A) $\mathrm{CD}^{+} \mathrm{CD}^{+}$subgroups of $\mathrm{T}$ lymphocytes for the experimental and control groups. (B) $\mathrm{CD}^{+} \mathrm{CD} 8^{+}$subgroups of $\mathrm{T}$ lymphocytes examined for the experimental and control groups. (C) $\mathrm{CD} 3{ }^{-} \mathrm{CD} 56^{+}$subgroups of natural killer (NK) cells examined for the experimental and control groups. COS, chitooligosaccharides; NAG, N-acetyl-D-glucosamine.

\section{Results}

COS and NAG induce PBMC proliferation. To examine whether COS and NAG can affect the proliferation of PBMCs, we cultured the PBMCs with COS and NAG at various concentrations. As shown in Fig. 1A and B, COS $(300 \mu \mathrm{g} / \mathrm{ml})$ and NAG $(300 \mu \mathrm{g} / \mathrm{ml})$ induced the proliferation of the PBMCs in comparison with the control $(\mathrm{P}<0.05)$. NAG at a concentration of $500 \mu \mathrm{g} / \mathrm{ml}$ also induced the proliferation of the PBMCs, but not so much as COS and NAG at the concentration of $300 \mu \mathrm{g} / \mathrm{ml}$, possibly due to the low molecule weight of NAG. These results suggest that COS and NAG induce PBMC proliferation in vitro.

COS and NAG inhibit apoptosis of PBMCs. To determine the effect of COS and NAG on the apoptosis of PBMCs, AO/EB staining was performed and the cells with a different redox status were counted. As shown in Table I, the apoptotic rates of the PBMCs treated with COS at the concentrations of 500, 300,100 and $50 \mu \mathrm{g} / \mathrm{ml}$ were $10.0 \pm 1.5,1.5 \pm 0.5,6.0 \pm 1.5$ and $11.5 \pm 2.0 \%$, respectively. The apoptotic rates of the PBMCs treated with NAG at the concentrations of 500, 300, 100 and $50 \mu \mathrm{g} / \mathrm{ml}$ were $9.0 \pm 1.5,2.0 \pm 0.5,4.5 \pm 1$ and $13.0 \pm 2.5 \%$, respectively. The apoptotic rates of the PBMCs treated with COS or NAG were significantly lower than the apoptotic rate of $38.5 \pm 3.5 \%$ for the PBMCs treated with the culture medium without COS or NAG. These results suggest that COS and NAG inhibit the apoptosis of PBMCs, with the most effective inhibition at the concentration of $300 \mu \mathrm{g} / \mathrm{ml}$.

COS and NAG affect antibody expression in leukomonocytes. To determine the effect of COS and NAG on the antibody
Table I. Effect of COS and NAG on PBMC apoptosis.

\begin{tabular}{lc} 
Group & Apoptotic rate $(\%)$ \\
\hline Negative control & $38.5 \pm 3.5$ \\
COS $500 \mu \mu \mathrm{g} / \mathrm{ml}$ & $10.0 \pm 1.5^{\mathrm{a}}$ \\
COS $300 \mu \mathrm{g} / \mathrm{ml}$ & $1.5 \pm 0.5^{\mathrm{b}}$ \\
COS $100 \mu \mathrm{g} / \mathrm{ml}$ & $6.0 \pm 1.5^{\mathrm{b}}$ \\
COS $50 \mu \mathrm{g} / \mathrm{ml}$ & $11.5 \pm 2.0^{\mathrm{a}}$ \\
NAG $500 \mu \mathrm{g} / \mathrm{ml}$ & $9.0 \pm 1.5^{\mathrm{a}}$ \\
NAG $300 \mu \mathrm{g} / \mathrm{ml}$ & $2.0 \pm 0.5^{\mathrm{b}}$ \\
NAG $100 \mu \mathrm{g} / \mathrm{ml}$ & $4.5 \pm 1.0^{\mathrm{b}}$ \\
NAG $50 \mu \mathrm{g} / \mathrm{ml}$ & $13.0 \pm 2.5^{\mathrm{a}}$
\end{tabular}

${ }^{\mathrm{a}} \mathrm{P}<0.05$ vs. control; ${ }^{\mathrm{b}} \mathrm{P}<0.01 \mathrm{vs}$. control. $\mathrm{COS}$, chitooligosaccharides; NAG, N-acetyl-D-glucosamine.

expression in leukomonocytes, PBMCs were treated with COS or NAG and flow cytometry was performed. As shown in Fig. 2, following treatment with $\mathrm{COS}$ or NAG, at the concentrations of 300,100 and $50 \mu \mathrm{g} / \mathrm{ml}$, the proportion of the PBMCs that expressed CD3-CD4, CD3-CD8 and CD3-CD56 antibodies increased.

The percentage of $\mathrm{CD}^{+}$cells was more than $90 \%$, suggesting that PBMCs cultured in vitro were mostly $\mathrm{T}$ lymphocytes. COS at the dose of $300 \mu \mathrm{g} / \mathrm{ml}$ and NAG at the dose of 100 and $300 \mu \mathrm{g} / \mathrm{ml}$ induced the differentiation of T leukomonocytes that express the CD4 antibody $(\mathrm{P}<0.05)$, but not the CD8 antibody. COS $(300$ or $100 \mu \mathrm{g} / \mathrm{ml})$ and NAG (300 $\mu \mathrm{g} / \mathrm{ml})$ significantly 
Table II. Changes in weight, and thymus and spleen indexes in each group after 15 days of COS or NAG administration by gavage.

\begin{tabular}{lcccc}
\hline Group & Change in weight $(\mathrm{g})$ & Thymus index $(\%)$ & Spleen index $(\%)$ & Tumor weight $(\mathrm{g})$ \\
\hline Normal control & $3.64 \pm 0.75$ & $0.257 \pm 0.012$ & $1.013 \pm 0.071$ & - \\
Negative control & $0.89 \pm 0.09^{\mathrm{a}}$ & $0.109 \pm 0.006^{\mathrm{a}}$ & $0.615 \pm 0.037^{\mathrm{a}}$ & $2.64 \pm 0.38$ \\
Positive control & $1.48 \pm 0.33^{\mathrm{a}}$ & $0.128 \pm 0.009^{\mathrm{a}}$ & $0.677 \pm 0.082^{\mathrm{a}}$ & $1.27 \pm 0.13^{\mathrm{a}}$ \\
COS $100 \mu \mathrm{g} / \mathrm{ml}$ & $1.97 \pm 0.45^{\mathrm{a}}$ & $0.158 \pm 0.011^{\mathrm{a}}$ & $0.984 \pm 0.053$ & $1.24 \pm 0.26^{\mathrm{a}}$ \\
COS $300 \mu \mathrm{g} / \mathrm{ml}$ & $3.52 \pm 0.91$ & $0.242 \pm 0.014$ & $1.016 \pm 0.079$ & $0.76 \pm 0.21^{\mathrm{b}}$ \\
COS $500 \mu \mathrm{g} / \mathrm{ml}$ & $3.58 \pm 0.86$ & $0.239 \pm 0.015$ & $1.247 \pm 0.085^{\mathrm{a}}$ & $1.05 \pm 0.37^{\mathrm{a}}$ \\
NAG $100 \mu \mathrm{g} / \mathrm{ml}$ & $2.386 \pm 0.71^{\mathrm{a}}$ & $0.134 \pm 0.012^{\mathrm{a}}$ & $0.893 \pm 0.068^{\mathrm{a}}$ & $1.36 \pm 0.38^{\mathrm{a}}$ \\
NAG $300 \mu \mathrm{g} / \mathrm{ml}$ & $3.77 \pm 0.79$ & $0.243 \pm 0.007$ & $1.098 \pm 0.064$ & $0.77 \pm 0.23^{\mathrm{a}}$ \\
NAG $500 \mu \mathrm{g} / \mathrm{ml}$ & $3.85 \pm 0.92$ & $0.185 \pm 0.008^{\mathrm{a}}$ & $1.214 \pm 0.057^{\mathrm{a}}$ & $0.74 \pm 0.25^{\mathrm{b}}$ \\
\hline
\end{tabular}

${ }^{\mathrm{a}} \mathrm{P}<0.05 ;{ }^{\mathrm{b}} \mathrm{P}<0.01$. COS, chitooligosaccharides; NAG, N-acetyl-D-glucosamine.

Table III. Tumor inhibition rate in each group after 15 days of COS or NAG administration by gavage.

\begin{tabular}{lc}
\hline Group & Inhibition rate $(\%)$ \\
\hline Positive control & $51.89 \pm 3.32$ \\
COS $100 \mu \mathrm{g} / \mathrm{ml}$ & $53.03 \pm 3.16$ \\
$\operatorname{COS} 300 \mu \mathrm{g} / \mathrm{ml}$ & $71.21 \pm 2.96^{\mathrm{a}}$ \\
$\mathrm{COS} 500 \mu \mathrm{g} / \mathrm{ml}$ & $60.22 \pm 2.74$ \\
$\mathrm{NAG} 100 \mu \mathrm{g} / \mathrm{ml}$ & $48.48 \pm 2.52$ \\
NAG $300 \mu \mathrm{g} / \mathrm{ml}$ & $70.83 \pm 2.59^{\mathrm{a}}$ \\
NAG $500 \mu \mathrm{g} / \mathrm{ml}$ & $71.97 \pm 3.63^{\mathrm{a}}$ \\
\hline
\end{tabular}

${ }^{\mathrm{a}} \mathrm{P}<0$.05. COS, chitooligosaccharides; NAG, N-acetyl-D-glucosamine.

increased the amount of the CD3-CD56 ${ }^{+}$subgroup of NK cells $(\mathrm{P}<0.05)$.

Antitumor activity, thymus and spleen indexes. The thymus and spleen are important immune organs and are closely related with immune functions and the antitumor activity. The change in weight of the animals is also an important indication of immune function. The results of the changes in weight, and thymus and spleen indexes are shown in Table II. The changes in weight of the group of $300 \mathrm{mg} / \mathrm{kg} \mathrm{COS}, 500 \mathrm{mg} / \mathrm{kg} \mathrm{COS}$, $300 \mathrm{mg} / \mathrm{kg}$ NAG and $500 \mathrm{mg} / \mathrm{kg}$ NAG were similar to those of the normal control group, while the increased weights of the positive control group and the negative control group were significantly less than those of the normal control group $(\mathrm{P}<0.05)$. The tumor inhibition rates are shown in Table III. The tumor inhibition rates of the groups administered with $100 \mathrm{mg} / \mathrm{kg} \mathrm{COS}$ and 100 or $300 \mathrm{mg} / \mathrm{kg}$ NAG were significantly higher than those of the normal control group $(\mathrm{P}<0.05)$.

The results relating to the thymus index were similar to those relating to weight. The results relating to the spleen index showed that the spleen index of the group of $500 \mathrm{mg} / \mathrm{kg} \mathrm{COS}$, $100 \mathrm{mg} / \mathrm{kg} \mathrm{NAG}$ and $500 \mu \mathrm{g} / \mathrm{ml}$ NAG was significantly higher than that of the normal control group $(\mathrm{P}<0.05)$, while the spleen index of the positive and negative control group was signifi- cantly lower than that of the normal control group $(\mathrm{P}<0.05)$. The obvious inhibitory effect on tumor growth was observed in the positive group, the groups of $300 \mu \mathrm{g} / \mathrm{ml} \mathrm{COS,} 500 \mathrm{mg} / \mathrm{kg}$ COS, $300 \mathrm{mg} / \mathrm{kg} \mathrm{NAG}$ and $500 \mathrm{mg} / \mathrm{kg}$ NAG $(\mathrm{P}<0.05)$.

COS and NAG upregulate NK cell activity and IL-2 and IFN- $\gamma$ levels. To investigate the effect of COS and NAG on the immunological activity of the animals, NK activity was evaluated. As shown in Fig. 3A, the NK activity of the group of $500 \mathrm{mg} / \mathrm{kg}$ COS and 300 or $500 \mathrm{mg} / \mathrm{kg}$ NAG was much higher than that of the positive control group $(\mathrm{P}<0.05)$, while the NK activity of the negative control group was much lower than that of the positive control group $(\mathrm{P}<0.05)$.

The secretory concentration of IL- 2 and IFN- $\gamma$ was examined by ELISA assays; the results of IL-2 are shown in Fig. 3B and those of IFN- $\gamma$ are shown in Fig. 3C. The secretory concentration of IL-2 in the serum of the COS group (all doses) and the 300 and $500 \mathrm{mg} / \mathrm{kg} \mathrm{NAG}$ groups was much higher than that of the normal, positive control and negative groups $(\mathrm{P}<0.05)$. The secretory concentration of IFN- $\gamma$ in the serum in the positive group and the group of $300 \mathrm{mg} / \mathrm{kg} \mathrm{COS}, 500 \mathrm{mg} / \mathrm{kg} \mathrm{COS}$, $300 \mathrm{mg} / \mathrm{kg}$ NAG and $500 \mathrm{mg} / \mathrm{kg}$ NAG was much higher than that of the normal and negative groups $(\mathrm{P}<0.05)$.

Immunohistochemistry for detection of VEGF expression. The immunohistochemistry staining of the tumors from each group is shown in Fig. 4. The negative control and positive control groups were both stained positively for VEGF, which is the marker of angiogenesis. No obvious positive staining was observed in the experimental groups of both COS and NAG (all doses). The negative staining in the COS and NAG groups revealed that COS and NAG inhibited the expression of VEGF in the tumors. VEGF is a very important molecule in the pathway of angiogenesis. The inhibition of the expression of VEGF can affect tumor angiogenesis. Therefore, it is suggested that COS and NAG reduce tumor growth through the inhibition of VEGF expression in tumors.

\section{Discussion}

Certain studies have reported on the apoptosis-inducing effects of COS and NAG. Lee et al reported the cytotoxicity of amino 

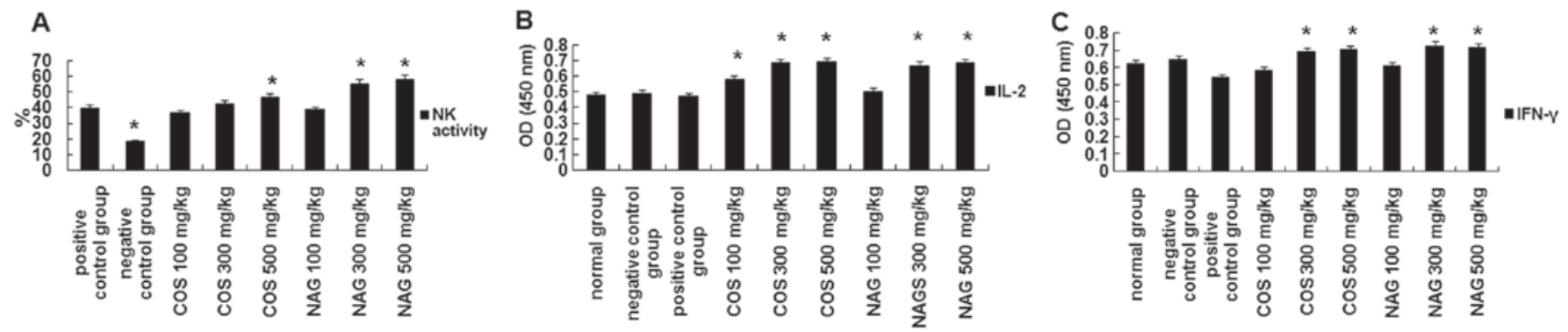

Figure 3. (A) The natural killer (NK) activity in each group after 15 days of chitooligosaccharide (COS) or N-acetyl-D-glucosamine (NAG) administration by gavage. (B) The secretory concentration of interleukin-2 (IL-2) in the serum of each group after 15 days of COS or NAG administration by gavage. (C) The secretory concentration of interferon- $\gamma(\mathrm{IFN}-\gamma)$ in the serum from each group after 15 days of COS or NAG administration by gavage.

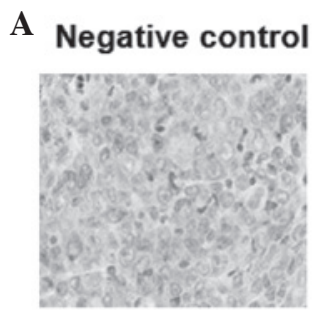

$0.7717 \pm 0.0371$

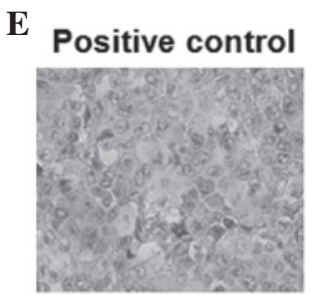

$0.3650 \pm 0.0846$

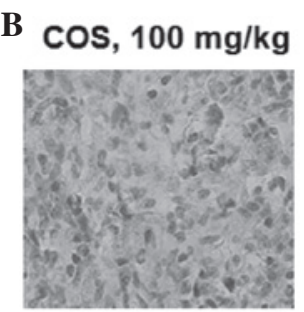

$0.1883 \pm 0.0444^{*}$
$\mathrm{C}$

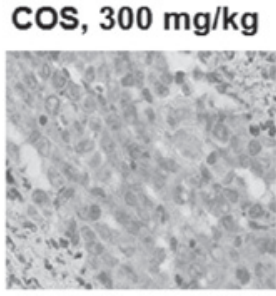

$0.3100 \pm 0.0429^{*}$

G

F NAG, $100 \mathrm{mg} / \mathrm{kg}$

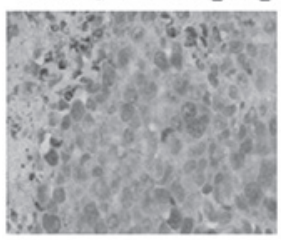

$0.3350 \pm 0.0579$

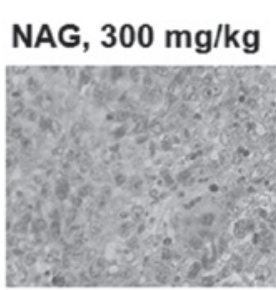

$0.1800 \pm 0.0576^{*}$
D

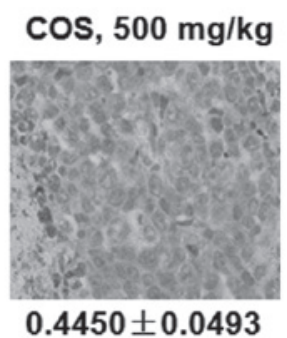

Figure 4. Light photomicrographs of the immunohistochemical staining for vascular endothelial growth factor (VEGF) of the 3 samples (x400). (A) Negative control group; (B-D) chitooligosaccharide (COS) group at the dose of 100, 300 and $500 \mathrm{mg} / \mathrm{kg}$; (E) positive control group; (F-H) N-acetyl-D-glucosamine (NAG) group at the dose of 100,300 and $500 \mathrm{mg} / \mathrm{kg}$. ${ }^{*} \mathrm{P}<0.05,{ }^{* *} \mathrm{P}, 0.01$ (COS group, $\mathrm{F}=86.42 ; \mathrm{NAG}$ group, $\mathrm{F}=73.76$ ).

derivatized chitosan derivatives in certain cancer cell lines, such as HepG2 and HeLa. However, the exact mechanisms by which these molecules exert their anticancer properties have yet to be identified (13). Previously, it was revealed that COS exerted anticancer activity by inducing apoptosis in the HL-60 cell line derived from a patient with acute promyelocytic leukemia (14). However, even though this mechanism of apoptosis induction has been suggested by some studies, other studies have presented DNA fragmentation results showing cells that have undergone necrosis but not apoptosis $(15,16)$. In this study, the results revealed that COS and NAG inhibited the growth of sarcoma 180 tumors and significantly improved the thymus and spleen indexes. This indicates that COS and NAG can protect the thymus and spleen. According to these results, it can be deduced that the antitumor activity of COS and NAG is possibly not due to the cytotoxicity of amino acids in COS or NAG, but due to their immunoregulation (17).

Tumor angiogenesis is a process in which tumors undergo microvascular growth and grow new blood vessels. Therefore, the inhibition of tumor angiogenesis is necessary to control the growth and migration of tumors. VEGF is an important moleculer marker of microvascular growth. It has been reported that sonic hedgehog homolog ( $\mathrm{SHH}$ ) signaling pathway plays an imprortant role in embryo development and angiogenesis. There would be an obvious decrease in both angiogenesis and in VEGF gene expression if the SHH signaling pathwas was inhibited. There are certain clinical data demonstrating the correlation between the SHH signaling pathway and VEGF expression (18); however, the mechanisms involved remain unknown. Other studies have reported that the PI3K signaling pathway is also closely correlated with VEGF expression in tumor cells (19). Therefore, the modulation of VEGF expression is a very complex process. There are several signaling pathways that paticipate in the modulation of VEGF expression. In our study, COS and NAG incorporated with the receptor as a ligand and played an important role in the modulation of one or several signaling pathways. Consequently, the signaling pathway and VEGF expression were inhibited, and tumor angiogenesis was restrained. In this study, the negative control and positive control groups were both positively stained for VEGF. The experimental group of both COS and NAG (all doses) had no obvious positive staining. Therefore, both COS and NAG inhibited tumor growth by inhibiting tumor angiogenesis.

The thymus, the main repository for differentiating and maturing $\mathrm{T}$ cells, plays an important role in the immune system. The spleen, the largest peripheral immune organ, is the 
main repository for immune response. The number of B cells in the spleen accounts for 55\% of the total leukomonocytes, and the number of $\mathrm{T}$ cells in the spleen accounts for $40 \%$. In this study, COS and NAG at the dose of 300 and $500 \mu \mathrm{g} / \mathrm{ml}$ increased the weight of the spleen and thymus, and improved the body's immune system.

COS and NAG can activate macrophages, NK cells, neutrophile granulocytes, leukomonocytes and complementary systems, and can induce the secretion of a number of cytokines, which play an important role in the antitumor process. Certain studies ahve found that the antitumor effects of COS and NAG are due to the increased activity of NK lymphocytes, as observed in sarcoma 180-bearing mice (20). These results are in agreement with those from our study. In this study, COS and NAG promoted the differentiation of NK cells by the expression of the CD3-CD56 subgroup; NAG was more effective than $\mathrm{COS}$, however. COS and NAG also promoted the differentiation of $\mathrm{T}$ cells by the expression of the CD4 subgroup but not the $\mathrm{CD} 8$ subgroup.

IL-2 is the principal growth factor for T and NK lymphocytes and is responsible for regulating the magnitude and duration of the immune response (21). The importance of IL-2 as a key cytokine for T cell activation and immune function has extensive experimental support (22). The appropriate production of IL-2 is an important determinant of the magnitude of $\mathrm{T}$ cell-dependent immune responses (23). IFN- $\gamma$, generally secreted by T cells and NK cells, is a pleiotropic cytokine endowed with potent immunomodulatory effects on a variety of immune cells in vitro and in vivo $(1,24)$. This cytokine exerts its multiple biological activities by controlling either positively or negatively the expression of many genes and proteins (25). In this study, COS and NAG activated both NK cells and T cells with special subgroups, and induced the secretion of IL-2 and IFN- $\gamma$, thus improving the antitumor activity. These results are in agreement with those from the study by Maeda et al $(20,26)$.

In conclusion, both COS and NAG can inhibit tumor growth by promoting the secretion of IL- 2 and IFN- $\gamma$, compared with cyclophosphamide. COS and NAG can promote the proliferation, differentiation and cytokine secretion of leukomonocytes. The antitumor and immunoregulatory effect is dose-dependent. The antitumor effect is achieved by the indirect improvement of immunoregulation. In medical surgery, COS and NAG may be applied together as a anticancer drug and immunomodulator to promote the clinical application.

\section{Acknowledgements}

This study was supported by Ocean University of China. We thank Professor Wanshun Liu and Professor Baoqin Han from the Ocean University of China. We are also thankful to the colleagues of Affiliated Hospital of Qingdao University for their technical assistance.

\section{References}

1. Billiau A: Interferon- $\gamma$ : biology and role in pathogenesis Advances Immunol 62: 61-130, 1996.

2. Han YP, Zhao LH and Wu HM: Mechanism of ol igochitosaninduced macrophage activation. Zhejiang Da Xue Xue Bao Yi Xue Ban 35: 265-272, 2006 (In Chinese).
3. Ko S, Takeshi M, Yoshio O, Akio T, Shigeo S and Masuko S: Antitumor effect of hexa-N-acetylchitohexaose and chitohexaose. Carbohydr Res 151: 403-408, 1986.

4. Muzzarelli RAA: Chitin. Oxford Pergamon Press, London, pp262-270, 1977

5. Qin CQ, Du YM, Xiao L and Li Z: Enzymic preparation of water-soluble chitosan and their antitumor activity. Int J Biol Macromol 31: 111-117, 2002.

6. Hanahan D and Folkman J: Patterns and emerging mechanisms of the angiogenic switch during tumorigenesis. Cell 86: 353-364, 1996.

7. Xiao BG, Ma CG, Xu LY, Hans L and Lu CZ: IL-12/IFN- $\gamma /$ $\mathrm{NO}$ axis plays critical role in development of Th1-mediated experimental autoimmune encephalomyelitis. Mol Immnol 45: 1191-1196, 2008

8. Caroline B, Derek D, Fran B and Frances B: Involvement of both intrinsic and extrinsic pathways in IFN- $\gamma$-induced apoptosis that are enhanced with cisplatin. Eur J Cancer 41: 1474-1486, 2005.

9. Tsiavou A, Hatziagelaki E, Chaidaroglou A, Koniavitou K, Degiannis D and Raptis SA: Correlation between intracellular interferon- $\gamma($ IFN- $\gamma)$ production by $\mathrm{CD}^{+}$and $\mathrm{CD} 8^{+}$lymphocytes and IFN- $\gamma$ gene polymorphism in patients with type 2 diabetes mellitus and latent autoimmune diabetes of adults (LADA). Cytokine 31: 135-141, 2005.

10. Wang XB, Liu QH, Wang P, Tang W and Hao Q: Study of cell killing effect on S180 by ultrasound activating protoporphyrin IX. Ultrasonics 48: 135-140, 2008.

11. Cao L, Liu XZ, Qian TX, et al: Antitumor and immunomodulatory activity of arabinoxylans: a major constituent of wheat bran. Int J Biol Macromol 48: 160-164, 2011.

12. Nie XH, Shi BJ, Ding YT and Tao WY: Antitumor and immunomodulatory effects Weikangfu granule compound in tumor-bearing mice. Curr Ther Res 67: 138-150, 2006.

13. Lee JK, Lim HS and Kim JH: Cytotoxic activity of aminoderivatized cationic chitosan derivatives. Bioorg Med Chem Lett 12: 2949-2951, 2002.

14. Pae HO, Seo WG, Kim NY, et al: Induction of granulocytic differentiation in acute promyelocytic leukemia cells (HL-60) by watersoluble chitosan oligomer. Leuk Res 25: 339-346, 2001.

15. Prashanth KVH and Tharanathan RN: Depolymerized products of chitosan as potent inhibitors of tumor-induced angiogenesis. Biochim Biophys Acta 1722: 22-29, 2005.

16. Huang RH, Mendis E, Rajapakse N and Kim SK: Strong electronic charge as an important factor for anticancer activity of chitooligosaccharides (COS). Life Sci 78: 2399-2408, 2006.

17. Cao XM, Xu HJ, Shang M and Liu WS: Experimental study on antitumor activities and immunity regulation of chitooligosaccharide. J Harbin Univ Commerce (Natural Sciences Edition) 22: 8-10, 2006 .

18. He H, Zhang H, Li B, et al: Blockade of the sonic hedgehog signalling pathway inhibits choroidal neovascularization in a laser-induced rat model. J Huazhong Univ Sci Technolog Med Sci 30: 659-665, 2010.

19. Huang Y, Hua K, Zhou X, et al: Activation of the PI3K/AKT pathway mediates FSH-stimulated VEGF expression in ovarian serous cystadenocarcinoma. Cell Res 18: 780-791, 2008.

20. Maeda Y and Kimura Y: Antitumor effects of various lowmolecular weight chitosans are due to increased natural killer activity of intestinal intraepithelial lymphocytes in sarcoma 180-bearing mice. J Nutr 134: 945-950, 2004.

21. Lindholm CK: IL-2 receptor signaling through the Shb adaptor protein in T and NK cells. Biochem Biophys Res Commun 296: 929-936, 2002

22. Ma A, Koka R and Burkett P: Diverse functions of IL-2, IL-15, and IL-7 in lymphoid homeostasis. Ann Rev Immunol 24: 657-679, 2006.

23. Choi JM, Kim HJ, Lee KY, Choi HJ, Lee IS and Kang BY.: Increased IL-2 production in T cells by xanthohumol through enhanced NF-AT and AP-1 activity. Int Immunopharmacol 9: 103-107, 2009.

24. Yong HA and Hardy KJ: Role of interferon-gamma in immune cell regulation. J Leukoc Biol 58: 373-378, 1995.

25. Sandra G and Filippo B: IFN- $\gamma$ Expression in macrophages and its possible biological significance. Cytokine Growth Factor Rev 9: 117-123, 1998

26. Xu QS, Bai XF and Du YG: Progress on anti-tumor activity of oligochitosan and its derivates. Food and Drug 10: 60-62, 2008. 